\title{
DFT:B3LYP/3-21G theoretical insights on the confocal Raman experimental observations in skin dermis of healthy young, healthy elderly, and diabetic elderly women
}

Claudio Alberto Téllez Soto

Liliane Pereira

Laurita dos Santos

Ramu Rajasekaran

Priscila Fávero

Airton Abrahão Martin 


\title{
DFT:B3LYP/3-21G theoretical insights on the confocal Raman experimental observations in skin dermis of healthy young, healthy elderly, and diabetic elderly women
}

\author{
Claudio Alberto Téllez Soto, ${ }^{*}$ Liliane Pereira, Laurita dos Santos, Ramu Rajasekaran, ${ }^{\dagger}$ Priscila Fávero, and \\ Airton Abrahão Martin \\ University of Paraiba Valley, Institute of Research and Development, Laboratory of Biomedical Vibrational Spectroscopy, São José dos Campos, \\ 12244-000 São Paulo, Brazil
}

\begin{abstract}
In the confocal Raman spectra of skin dermis, the band area in the spectral region of proline and hydroxyproline varies according to the age and health condition of the volunteers, classified as healthy young women, healthy elderly women, and diabetic elderly women. Another observation refers to the intensity variation and negative Raman shift of the amide I band. To understand these effects, we adopted a model system using the DFT/B3LYP:3-21G procedure, considering the amino acid chain formed by glycine, hydroxyproline, proline, and alanine, which interacts with two and six water molecules. Through these systems, polarizability variations were analyzed to correlate its values with the observed Raman intensities of the three groups of volunteers and to assign the vibrational spectra of the skin dermis. As a way to correlate other experimental trends, we propose a model of chemical reaction of water interchange between the bonding amino acids, in which water molecules are attached with glucose by hydrogen bonds. The theoretical results are in accordance with the observed experimental trends. ๑ 2016 Society of Photo-Optical Instrumentation Engineers (SPIE) [DOI: 10.1117/1.JBO.21.12.125002]
\end{abstract}

Keywords: DFT/B3LYP:3-21G; in vivo confocal Raman spectroscopy; skin dermis.

Paper 160315R received May 20, 2016; accepted for publication Nov. 14, 2016; published online Dec. 8, 2016.

\section{Introduction}

In the dermis of healthy young women (HYW), collagen provides an ideal three-dimensional arrangement of the triple-helix. Its fibers' arrangements are compact, with the triple-helical domain in perfect condition. It presents a high amino acid content due to the presence of a large quantity of proline, an important compound that provides a rigid structure for the chains and that is responsible for tissue repair, collagen formation, and arteriosclerosis prevention. It has adequate stability due to the presence of water molecules, which play the role of a stabilizing agent by keeping its molecular conformation and mechanical properties. ${ }^{1}$ Water is an integral part of the collagen triplehelix, forming intramolecular bonds and promoting intermolecular bridges. Water also helps to keep the stability of the collagen structure. Moreover, it is responsible for the assembly of collagen fibers through the formation of a hydration cylinder extended in the molecule, which mediates sets of collagen in fibrils. ${ }^{1-4}$ In the dermis of healthy elderly women (HEW), collagen density decreases and their three-dimensional arrangement shows remarkable changes. For example, the fiber bundles become thinner. ${ }^{5}$ Additionally, chains lose their compactness and firmness features, allowing water molecules to penetrate those chains and remaining bound only in the conformational structure and without exerting a stabilization function. This

\footnotetext{
*Address all correspondence to: Claudio A. Téllez Soto, E-mail: cayotellez@ gmail.com

${ }^{\dagger}$ Current address: Bannari Amman Institute of Technology, Department of
} Physics, Sathyamangalam 638402, India makes the water content in the dermis significantly higher in the elderly than in the young human skin. ${ }^{1-3}$

Elderly diabetic women, beside presenting a reduction of collagen synthesis by the skin chronological aging, are heavily affected by the phenomenon of glycation caused by the sustained hyperglycemia. The advanced glycation end products (AGEs) are substances formed by a heterogeneous class of molecules, which cause the degradation of type I collagen leading to the loss of dermal biomechanics and the appearance of wrinkles. The main changes that occur in collagen are due to chronological aging and the presence of these glicotoxines, specifically in the region of proline, hydroxyproline, and amide I. The main AGEs of the glycation process in dermis are pentosidine and glucosepane, which have been characterized by in vivo confocal Raman spectroscopy in our previous report. ${ }^{4}$ The main effect observed in the Raman data is concerned with the intensity variation of the proline and hydroxyproline bands and the negative Raman shift of the amide $\mathrm{I}^{4}$

In vivo characterization of human skin by confocal Raman spectroscopy has been reported by many authors, showing its potentiality to the analysis of the skin structure, to diagnosis procedures, and to the study of several aspects and processes like glycation, collagen structure, aging, permeation of products, and cosmetic effects. ${ }^{5-14}$ Hashmi et al. ${ }^{13}$ carried out a study on plantar skin in type II diabetes that focused on protein glycation and biomechanical properties of plantar epidermis. Avery and Bailey carried out a study on the effects of the Maillard reaction on the physical properties and cell interactions. ${ }^{15}$ 
Hence, our particular interest in this area is to use confocal Raman spectroscopy to achieve a qualitative determination of the water content in collagen, to identify AGEs, and to detect collagen degradation. In this paper, we focused on the water content in the collagen fibers in the skin dermis of 30 volunteers of different ages: HYW, HEW, and diabetic elderly women (DEW). To understand these effects, we present a computational modeling of the water interchange of four principal amino acid components of collagen with glucose, using the DFT/B3LYP:3$21 \mathrm{G}$ procedure and considering the amino acid chain formed by glycine, hydroxyproline, proline, and alanine, which interacts with two and six water molecules.

\section{Materials and Methods}

This research was carried out by following the Guidelines and Norms Regulating Research Involving Human Subjects of the National Council of Ethics in Research/Ministry of Health Resolution 466/12. The Research Ethics Committee (Brazil) under the General Certificate for Assessment Ethics CAAE approved the project: 03826112.2.0000.0077 and Embodied Opinion no. 132.812/12 in favor of the research. All participants were informed about the important research and agreed and signed the consent form called "consent form free and clarified."

\subsection{Selection of Volunteers}

Thirty women volunteers were selected as research subjects; they were further equally divided into three groups: (1) 10 elderly volunteers with type II diabetes mellitus (DEW) in the age group of 65 to 80 years; (2) $10 \mathrm{HYW}$ in the age group of 20 to 33 years; and, (3) $10 \mathrm{HEW}$ in the age group of 65 to 80 years.

\subsection{In Vivo Confocal Raman Spectroscopy}

Skin evaluations were performed by using a confocal Raman system from Rivers Diagnostics ${ }^{\circledR}$ (Model 3510 Skin Composition Analyzer) coupled to a laser of excitation wavelength $785 \mathrm{~nm}$. The laser light was focused on the skin with a microscope objective $(40 \times)$ located under the quartz window. The power at the sample was measured as $20 \mathrm{~mW}$. The Raman spectra were measured from 70 to $130 \mu \mathrm{m}$ in depth to reach the skin dermis region, with an exposure time of $45 \mathrm{~s}$ and two accumulations.

\subsection{Data Treatment}

The subsequent preprocessing (baseline correction, four points smoothing, and vector normalization) was carried out using the Labspec software from Horiba Jobin Yvon, Lille, France and the OMNIC software from Thermo Nicolet, Madison, Wisconsin. Second derivative in conjunction with band deconvolution analysis was used to assign hidden bands in specific regions of the Raman confocal spectra of all the volunteers.

\subsection{Computational Modeling}

For an interpretative model that could represent an approximate extension of the dermis collagen content in elderly women, where water is present, we elected the computational model formed by an amino acid chain: glycine-hydroxyproline-proline-alanine with six water molecules around the structure, abbreviated as Gly.HP.P.Ala. $6 \mathrm{H}_{2} \mathrm{O}$. By this model, the hydrogen bond among water molecules is less extensive, and by this quantity, they form less hydrogen bonds among themselves. The system Gly.HP.P.Ala. $6 \mathrm{H}_{2} \mathrm{O}+$ glucose represents the reactional system and cannot be considered as an interpretative model of the DEW due to its higher polarizability. (The band profile intensity of the spectra in this case is higher than the correlative intensity for the Raman spectra of skin dermis of healthy young and elderly women.) Based on the fact that the glucose solubility in water is higher than the solubility of collagen in water and the decrease of collagen content due to the higher collagen degradation on the skin dermis in elderly diabetic women by the glycation process, Gly.HP.P.Ala. $6 \mathrm{H}_{2} \mathrm{O}$ represents one of the reagents and glucose represents the other. Therefore, we propose a chemical reaction of water interchange between the amino acids glycine, proline, hydroxyproline, and alanine with glucose. The proposed chemical reaction can be written as follows:

$$
\begin{aligned}
& \text { Gly.HP.P.Ala. } 6 \mathrm{H}_{2} \mathrm{O}+\text { glucose } \\
& \quad \Rightarrow \text { Gly.HP.P.Ala. } 2 \mathrm{H}_{2} \mathrm{O}+\text { glucose } .4 \mathrm{H}_{2} \mathrm{O} .
\end{aligned}
$$

In the above equation, Gly.HP.P.Ala. $6 \mathrm{H}_{2} \mathrm{O}$ represents the case of the HEW and Gly.HP.P.Ala. $2 \mathrm{H}_{2} \mathrm{O}$ represents the DEW. These models would be compatible with the polarizability of the systems. In all the cases, the polarizability of the model representing the elderly diabetic women must be a little higher than that representing the young women, which can be described as Gly.HP.P.Ala. However, we can also consider the comparatively less concentration of collagen in the samples of the DEW to match the observed Raman intensities among all volunteers.

Calculations were also done for proline and hydroxyproline, in which the assignments consider the variation of the equilibrium of structural parameters (bond lengths and angle between bonding atoms) in the framework structure of both amino acids. All the molecules considered in the modeling process are independent noninteracting units. For geometry optimization, the density functional theory (DFT) with the functional B3LYP was used with the $3-21 \mathrm{G}$ basis set in Gaussian 03 program. ${ }^{16}$ All calculations have been optimized from several initial geometries to guarantee the global minimal energy structures. After this procedure, the vibrational calculations were performed and no imaginary mode was observed. Characteristic normal modes in the amide I and in the proline-hydroxyproline region were visualized using the graphical Chemcraft program.

\section{Results and Discussion}

Figure 1 shows the averaged confocal Raman spectra of the amide I region (1725 to $1500 \mathrm{~cm}^{-1}$ ) and the characteristic region of proline and hydroxyproline $\left(1000\right.$ to $\left.800 \mathrm{~cm}^{-1}\right)$ of the three group of volunteers.

Figure 2 shows the results of the second derivative of the averaged confocal Raman spectra of the three group of volunteers. For the DEW volunteers, the second derivative spectra are a little more complex showing additional peaks (due to the presence of AGEs) compared with the second derivative spectra of the HEW and HYW volunteers.

To determine the collagen degradation for each group, the area of the band profile from proline and hydroxyproline was determined. According to Goisses (2007), the proline content in type I collagen is higher than the hydroxyproline content by $11 \% .{ }^{17}$ Therefore, when the collagen degradation occurs through the glycation process, the confocal Raman analysis of the vector-normalized spectra of DEW, HEW, and HYW shows that the proline contents, evidenced by the band at $938 \mathrm{~cm}^{-1}$, 


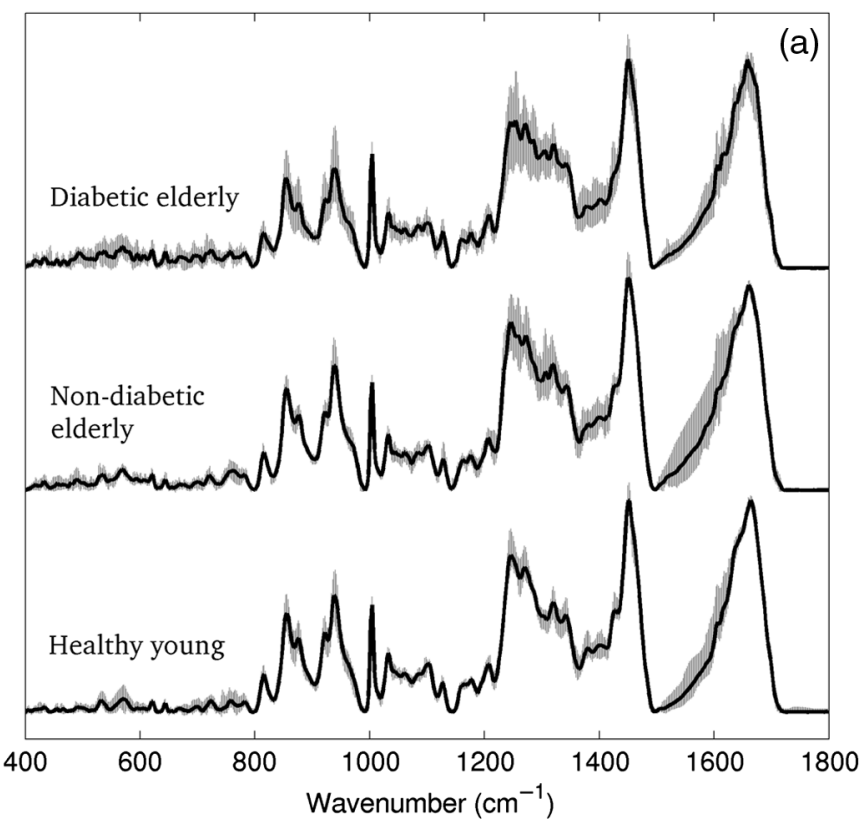

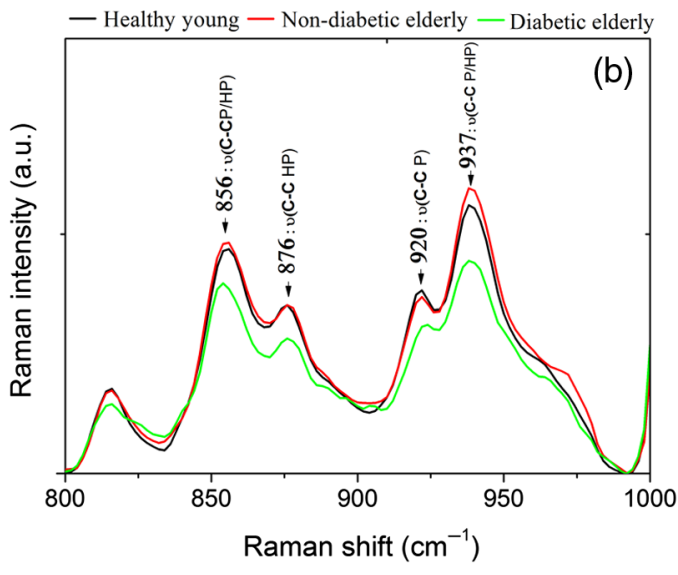

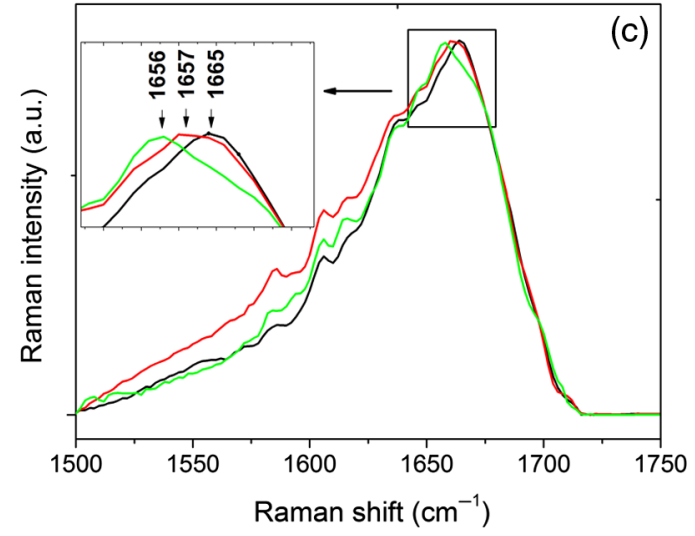

Fig. 1 Vector normalized Raman confocal spectra of (a) average and standard deviation of skin dermis for three groups of study participants, (b) proline and hydroxyproline $\left(1000\right.$ to $\left.800 \mathrm{~cm}^{-1}\right)$ region, and (c) skin dermis in the spectral region of amide I (1725 to $1500 \mathrm{~cm}^{-1}$ ): (1) black line: young women; (2) red line: elderly women; (3) green line: DEW.

have higher area in the spectra of HYW (45\%) than in HEW (36\%) and DEW (20\%). However, the total area of the $\mathrm{HP}$ and $\mathrm{P}$ spectral region has the following values: 42.12 (HYW), 38.86 (HEW), and 30.88 (DEW) in [Raman intensity (arbitr.units) $\times \mathrm{cm}^{-1}$ ] units. These values indicate the collagen degradation contents. For the HEW volunteers, the collagen content in the skin dermis appears to be $8 \%$ lower than the values found for the HYW volunteers. For the diabetic women, the collagen degradation reached $27 \%$.

\subsection{Experimental and Calculated Hydroxyproline and Proline Bands}

In this section, bands in the higher energy region between 2500 and $3600 \mathrm{~cm}^{-1}$ are not considered because we are not dealing with protein, lipids, and total water content in the skin dermis region. We restricted our research to collagen concentration, which expressive bands become as a result of the presence of proline and hydroxyproline amino acids and are present in the 800 to $1000 \mathrm{~cm}^{-1}$ spectral region.

In our earlier paper, we discussed the vibrational assignment of these amino acids based on assignments of other authors and in a qualitative approach, indicating the principal internal coordinates (stretching and bending), which has higher variations in the normal modes of these two amino acids. ${ }^{18}$ In the region between 1000 and $800 \mathrm{~cm}^{-1}$, DFT calculations predict the presence of six bands for $\mathrm{P}$ and $\mathrm{HP}$, in which the wavenumbers agree with previous assignments from literature, but in several cases, the vibrational assignments are doubtful. ${ }^{19-21}$ For the vibrational assignment of proline, we selected eight stretching coordinates and ten bending internal coordinates and for hydroxyproline, 8 stretching and 11 in-plane bending internal coordinates. In these selections, the internal coordinates that are representative of higher energy vibrations were neglected. The further assignments are based on the percentage deviation of the geometric parameter (PDPG) analysis. ${ }^{22-24}$ All the experimental Raman bands come from the deconvoluted spectra showed in Fig. 2. Results of wavenumbers from the DFT:B3LYP/3-21G procedure were scaled by 0.965 . The symbol $(\%)$ indicates the percentage variation of the bond lengths and angles, and it is given between parentheses. Our assignments in this particular spectral region are presented in Table 1.

The description of the different normal modes of $\mathrm{P}$ and HP is explained in Table 1, where the participation of different internal coordinates in the normal modes is given in percentage values (\%). The normal mode of proline at 959 (DEW), 957 (HEW), and $960(\mathrm{HYW}) \mathrm{cm}^{-1}$ is found in $37 \%, 41 \%$, and $22 \%$ of the Raman confocal spectra of HYW, HEW, and DEW, respectively, and has been interpreted as follows: for the HYW volunteers, $37 \%$ of contents represent the collagen concentration; $41 \%$ of contents are expressive and indicate the participation of the $-\mathrm{C}=\mathrm{O}$ group of the carboxylate of hydroxyproline forming hydrogen bond with water with a consequence of increase in polarizability. The same trend was found for the band under amide I normalization; 22\% in DEW represent collagen degradation and loss of water by the presence of glucose. The normal 

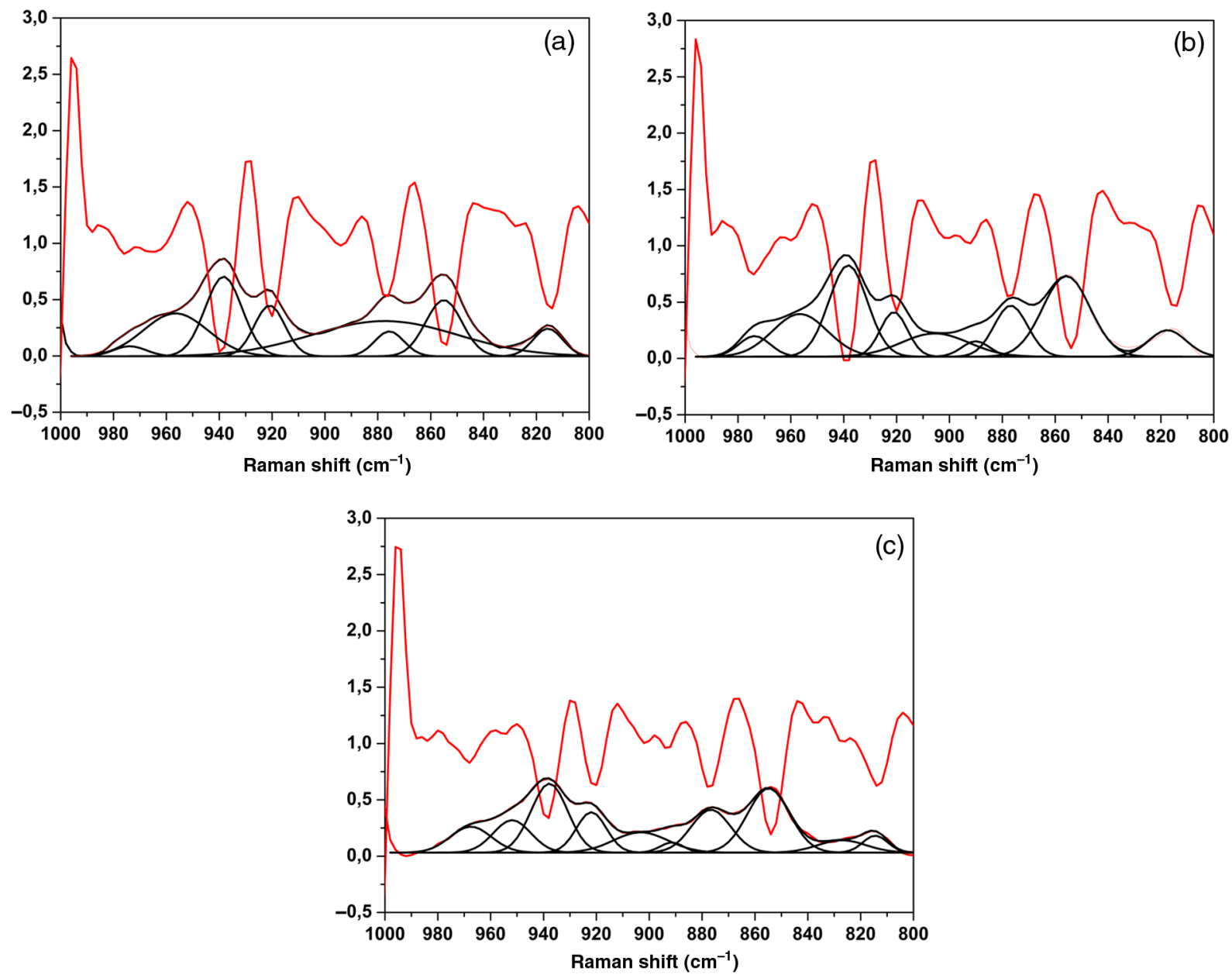

Fig. 2 Second derivative and band deconvolution spectra (Gaussian fitting) of (a) HYW, (b) HEW, and (c) DEW in the spectral region of proline and hydroxyproline $\left(1000\right.$ to $\left.800 \mathrm{~cm}^{-1}\right)$. Red and black curves are the second derivative and band deconvolution spectra, respectively.

mode found at 939 (HYW), 938 (HEW), and 938 (DEW) $\mathrm{cm}^{-1}$ participates with $45 \%, 36 \%$, and $20 \%$, respectively, which indicates that the decreasing collagen concentration.

For hydroxyproline, the observed Raman band at 921 (HYW), 921 (HEW), and $922(\mathrm{DEW}) \mathrm{cm}^{-1}$ participates with $27 \%, 34 \%$, and $39 \%$, respectively, indicating increasing water content by hydrogen bond formation, and the assignment is given in Table 1. The calculated band at $905 \mathrm{~cm}^{-1}$ for proline and at $913 \mathrm{~cm}^{-1}$ for hydroxyproline, which was observed at 914 (HYW) 33\%, 904 (HEW) 46\%, and $905 \mathrm{~cm}^{-1}$ (DEW) 21\%, is an indication of water content among the collagen fibers, principally in the case of HEW.

It also indicates the collagen degradation in the DEW with consequent loss of water by competitive interchange with glucose.

Raman bands at 890 (HYW), 892 (HEW), and $893 \mathrm{~cm}^{-1}$ (DEW) with 69.9 and $22 \%$ area show collagen degradation in the skin of the HEW and DEW volunteers.

The value of the band centered at $875 \mathrm{~cm}^{-1}$ is the assignment for hydroxyproline with area values of $30 \%, 41 \%$, and $29 \%$ for the HYW, HEW, and DEW, respectively. The $41 \%$ reflects water contents in HEW and the $29 \%$ in DEW implies collagen fiber's degradation and water contents. The band at $856 \mathrm{~cm}^{-1}$ (HYW), $855 \mathrm{~cm}^{-1}$ (HEW), and $854 \mathrm{~cm}^{-1}$ for (DEW) for the vector normalization participates with $39 \%, 33 \%$, and $28 \%$, respectively, can be assigned as the $\nu(\mathrm{CC})+\nu(\mathrm{CO})$ mode of proline. This band shows the collagen degradation of HEW and DEW. For proline, the calculated band at $819 \mathrm{~cm}^{-1}$ was correlated to the bands found at 821 (HYW), 822 (HEW), and $823(\mathrm{DEW}) \mathrm{cm}^{-1}$. This normal mode is considered an indication of hydrogen bond formation with water due to the increased intensity of the bands of the HEW and DEW volunteers.

Bands at 813 (DEW), 814 (HEW), and 814 (HYW) $\mathrm{cm}^{-1}$, assigned to hydroxyproline with area values representing the $44 \%, 36 \%$, and $20 \%$ for HYW, HEW, and DEW through vector normalization, agree well with the glycation process of proteins caused by hyperglycemia conducing the thermal denaturation of collagen. The integrated band areas for the HP/P spectral region for HYW, HEW, and DEW in the spectra were $43.12(38 \%)$, $39.74(35 \%)$, and $31.94(28 \%)$, respectively, in [Raman Intensity (Arbitr. Units) $\times \mathrm{cm}^{-1}$ ] units. The Maillard reaction, which describes the glycation product resulting from the reaction between the aldehyde function of glucose, ribose, or fructose with the amine free function of lysine or arginine of a protein, is well known ${ }^{26}$ and can be summarized as: $\mathrm{HO}-\mathrm{CH}_{2}-(\mathrm{HCOH})_{4} \mathrm{CHO}+$ $\mathrm{H}_{2} \mathrm{~N}-($ Lys or $\mathrm{Arg}) \Leftrightarrow \mathrm{H}_{2} \mathrm{O}+\mathrm{HO}-\mathrm{CH}_{2}-(\mathrm{HCOH})_{4} \mathrm{CH}=\mathrm{N}-$ (Lys or $\mathrm{Arg}) \Leftrightarrow \mathrm{HO}-\mathrm{CH}_{2}-(\mathrm{HCOH})_{4} \mathrm{CH}_{2}-\mathrm{NH}-($ Lys or $\mathrm{Arg}) \Rightarrow$ protein $-A G E$ or protein cross-link product. Pentosidine formation comes from oxidation and a subsequential reaction with ribose and collagen bound arginine. The other glycation product 
Table 1 Selected, calculated bands of proline $(\mathrm{P})$ and hydroxyproline $(\mathrm{HP})$ in the spectral region of 1000 to $800 \mathrm{~cm}^{-1}$. Experimental bands determined by band deconvolution analysis. Area band values in parentheses.

\begin{tabular}{|c|c|c|c|c|c|}
\hline Exp. HYW & Exp. HEW & Exp. DEW & DFT.(P) & DFT.(HP) & Assignment in the order $(\mathrm{P})$; (HP), or coincident assignment \\
\hline & & $982(0.54)$ & & & Glucosepane \\
\hline \multirow[t]{2}{*}{$973(0.74)$} & $\begin{array}{l}972(1.37) \\
974(1.62)\end{array}$ & & & & $\mathrm{C}-\mathrm{C}$ backbone (collagen assignment) ${ }^{20}$ \\
\hline & & $970(0.97)$ & & & Pentosidine, glucosepane \\
\hline \multirow[t]{2}{*}{$960(3.75)$} & $\begin{array}{l}957(4.17) \\
956(7.26)\end{array}$ & $959(2.17)$ & & 960 & $\nu(\mathrm{CC}) 14,0 \%+\nu(\mathrm{C}-\mathrm{COOH}) 12.5 \%+\delta(\mathrm{NC}[\mathrm{COOH}]) 10.1 \%$ \\
\hline & & $948(1.73)$ & 946 & & $\nu(\mathrm{CC}) 12.3 \%+\nu(\mathrm{CO}) 10.4 \%+\delta(\mathrm{NC}[\mathrm{COOH}]) 8.7 \% ; \nu(\mathrm{CC})$ proline $^{19}$ \\
\hline 939 (10.19) & $\begin{array}{l}938(8.11) \\
938(8.73)\end{array}$ & $938(4.49)$ & 928 & & $\nu(\mathrm{CC})$ ring $22.8 \%+\nu(\mathrm{CN})$ ring $19.0 \%+\delta(\mathrm{C}-\mathrm{C}-\mathrm{COOH}) 13.8 \%+\delta(\mathrm{CCC})$ ring \\
\hline $921(2.38)$ & $\begin{array}{l}921(2.98) \\
921(3.55)\end{array}$ & $922(3.48)$ & & 926 & $\nu(\mathrm{CC})$ ring $14.6 \%+\nu(\mathrm{CC}) 12.5 \%+\delta(\mathrm{N}-\mathrm{C}-\mathrm{COOH}) 10.1 \%+\nu(\mathrm{CN})$ ring $9.4 \%$ \\
\hline $914(1.84)$ & $\begin{array}{l}904(2.54) \\
905(3.94)\end{array}$ & $905(1.19)$ & 905 & 913 & $\begin{array}{l}\nu(\mathrm{CC}) \text { ring } 22.5 \%+\nu(\mathrm{CN}) \text { ring } 18.8 \%+\delta(\mathrm{C}-\mathrm{C}-\mathrm{COOH}) 13.6 \% \\
\nu(\mathrm{CN}) \text { ring } 20.3 \%+\nu(\mathrm{CC}) \text { ring } 11.3 \%+\delta(\mathrm{C}-\mathrm{N}-\mathrm{C}) 8.8 \%\end{array}$ \\
\hline \multirow[t]{2}{*}{$890(3.65)$} & $\begin{array}{l}892(0.46) \\
892(0.66)\end{array}$ & $893(1.17)$ & 880 & 895 & $\begin{array}{l}\nu(\mathrm{CC}) \text { ring } 22.5 \%+\nu(\mathrm{CN}) \text { ring } 18.89 \%+\delta(\mathrm{C}-\mathrm{C}-\mathrm{COOH}) 13.6 \% \\
\nu(\mathrm{CO}) 14.4 \%+\nu(\mathrm{CC}) \text { ring } 10.3 \%+\delta(\mathrm{C}-\mathrm{C}-\mathrm{COOH}) 10.0 \%\end{array}$ \\
\hline & & $881(0.37)$ & & & Pentosidine or glucosepane \\
\hline $875(3.60)$ & $\begin{array}{l}876(4.97) \\
876(6.17)\end{array}$ & $876(3.42)$ & & 865 & $\delta(\mathrm{CCC})$ ring $10.3 \%+\nu(\mathrm{CN})$ ring $9.8 \%+\delta(\mathrm{CCC})$ ring $9.8 \%$ \\
\hline \multirow[t]{2}{*}{$856(8.36)$} & $\begin{array}{l}855(7.03) \\
855(9.11)\end{array}$ & $854(5.94)$ & 847 & & $\nu(\mathrm{CC})$ ring $+\nu(\mathrm{CO})$ \\
\hline & $\begin{array}{l}837(0.24) \\
838(0.23)\end{array}$ & $840(8.73)$ & & & Deformation vibrations of amine groups ${ }^{25}$ \\
\hline $821(0.79)$ & $\begin{array}{l}822(0.83) \\
824(1.55)\end{array}$ & $823(1.62)$ & 819 & & $\begin{array}{l}\nu(\mathrm{CC}) \text { ring } 14.8 \%+\delta(\mathrm{CCN}) \text { ring } 10.7 \%+\nu(\mathrm{CC}) \text { ring } 9.7 \%+\nu(\mathrm{C}=\mathrm{O}) 9.1 \% \text {; } \\
\mathrm{P}, \mathrm{HP}^{18}\end{array}$ \\
\hline $814(1.09)$ & $\begin{array}{l}814(0.90) \\
814(1.41)\end{array}$ & $813(0.50)$ & & 813 & $\nu(\mathrm{CC})$ ring $25.3 \%+\nu(\mathrm{CO}) 15.4 \%$ \\
\hline
\end{tabular}

is glucosepane, which is formed by a nonoxidative reaction with collagen bound arginine. ${ }^{15}$

\subsection{Glycine-Hydroxyproline-Proline-Alanine Systems}

The other systems considered in our analysis to explain the experimentally observed trends in the Raman spectra of skin dermis of young, elderly, and elderly diabetic women are the following: glycine.hydroxy.proline.proline.alanine $6 \mathrm{H}_{2} \mathrm{O}$, abbreviated as GHPPAL, GHPPAL. $2 \mathrm{H}_{2} \mathrm{O}$; GHPPAL. $6 \mathrm{H}_{2} \mathrm{O}$; GHPPAl; glucose and glucose. $4 \mathrm{H}_{2} \mathrm{O}$, which also represent reagents and products of the water ligand interchange of the reaction:

$$
\begin{aligned}
\text { GHPPAl } .6 \mathrm{H}_{2} \mathrm{O}+\text { glucose } \Rightarrow & \text { GHPPAl } 2 \mathrm{H}_{2} \mathrm{O} \\
& + \text { glucose } .4 \mathrm{H}_{2} \mathrm{O} .
\end{aligned}
$$

These systems are shown in Fig. 3.

\subsection{Thermodynamic Considerations}

We computed the heat of formation and the Gibb free energy at $298 \mathrm{~K}$ of GHPPAl. $2 \mathrm{H}_{2} \mathrm{O}$ and glucose. $4 \mathrm{H}_{2} \mathrm{O}$ via an interchange of water as ligand. Corrected values by the zero point energy are given in Table 2.

From the values given in Table 2, we concluded that the proposed reaction of water interchange between the amino acid chain and glucose is exothermic and spontaneous. Furthermore, we evaluated the dipole moment $(\mu)$ and the polarizability $(\sigma)$ of these systems. Table 3 presents the calculated DFT/ B3LYP:3-21G values for the low triangle of the polarizability tensor $\sigma i j$. Dipole moments are in Debye units.

The DFT/B3LYP:3-21G calculations for the above systems give the same conclusions pointed out above for the HP.P. HP.P. $4 \mathrm{H}_{2} \mathrm{O}$ and HP.P. $2 \mathrm{H}_{2} \mathrm{O}$ systems described in an earlier paper. ${ }^{18}$ According to the polarizability values, in the Raman spectra of elderly women, the bands have high intensity compared with the Raman spectra of young women and with DEW. Moreover, the intensity of the bands for the elderly healthy women must be a little higher than the intensity of the 


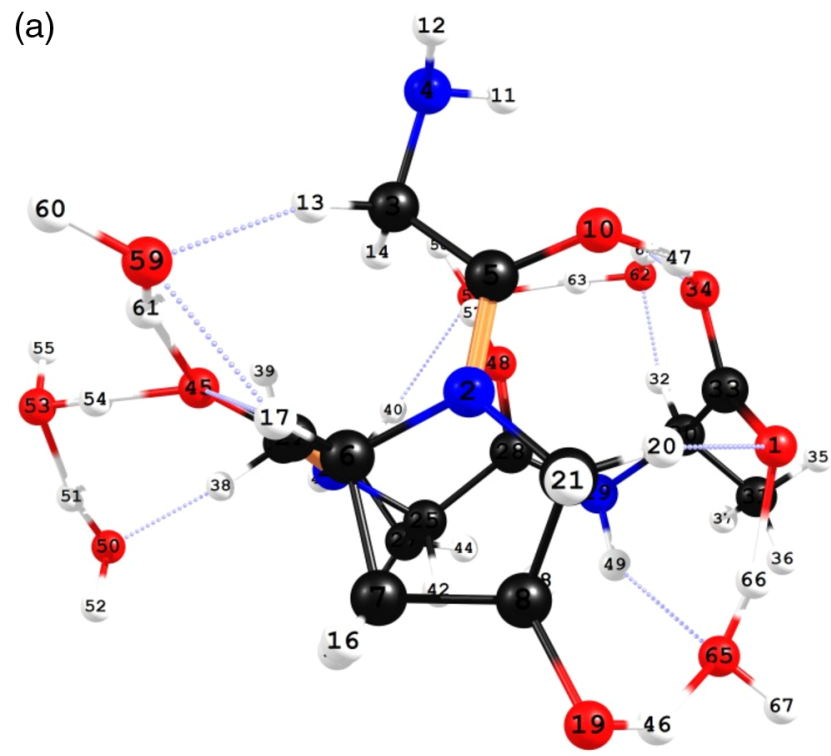

(c)

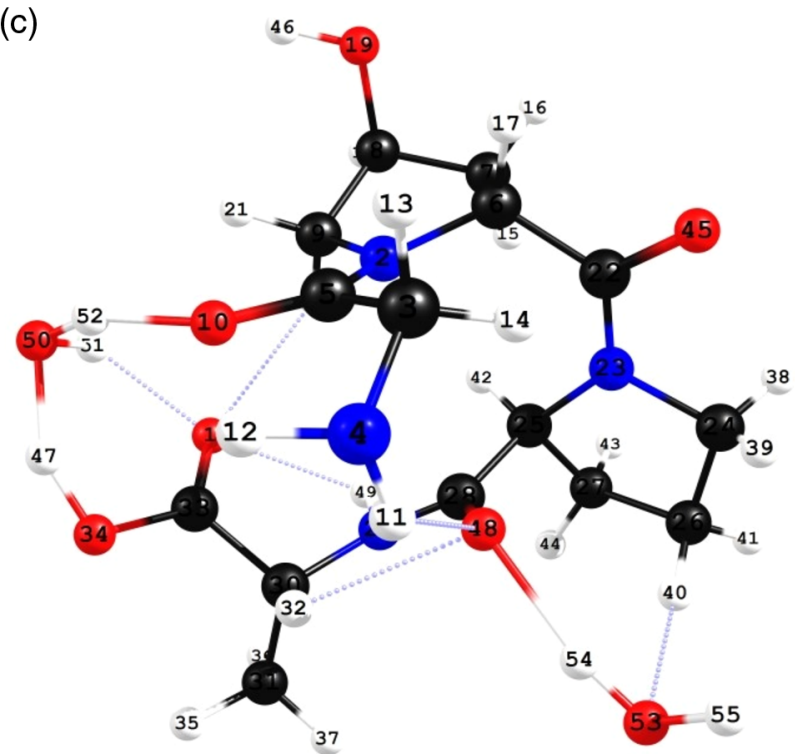

(b)

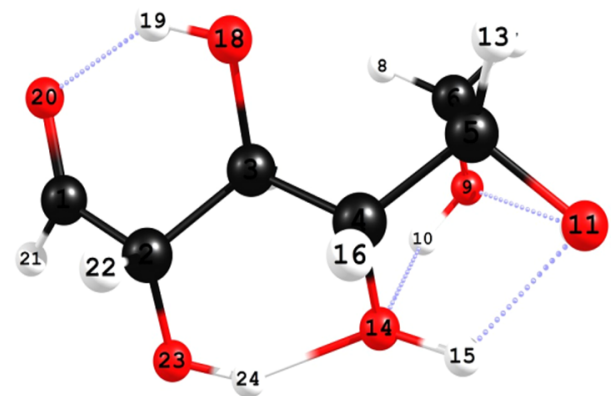

(d)

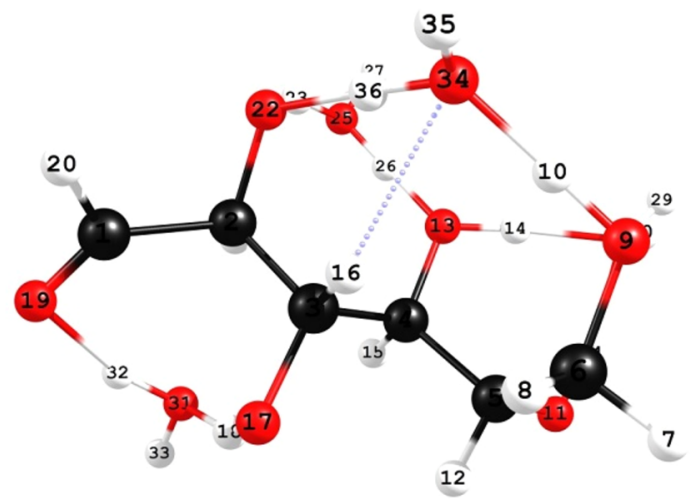

Fig. 3 Geometrical structure of the systems: (a) and (b) GHPPAla. $6 \mathrm{H}_{2} \mathrm{O}$ and glucose as reagents, and (c) and (d) GHPPAl. $2 \mathrm{H}_{2} \mathrm{O}$ and glucose. $4 \mathrm{H}_{2} \mathrm{O}$ as products of the reaction.

Table 2 Thermodynamics of the systems G.HP.P.Ala. $4 \mathrm{H}_{2} \mathrm{O}$, Glucose, G.HP.P.Ala. $2 \mathrm{H}_{2} \mathrm{O}$, and Glucose. $4 \mathrm{H}_{2} \mathrm{O}$.

\begin{tabular}{|c|c|c|c|c|}
\hline Chemical & $\begin{array}{c}\text { Eo+ } \\
\mathrm{H}^{\circ} \text { corr.(A.U.) }\end{array}$ & $\mathrm{Kcal} / \mathrm{mol}$ & $\begin{array}{c}\text { Eo }+ \\
G^{\circ} \text { corr.(A.U.) }\end{array}$ & $\mathrm{kcal} / \mathrm{mol}$ \\
\hline GHPPAI. $6 \mathrm{H}_{2} \mathrm{O}$ & -1705.011697 & & -1705.117782 & \\
\hline Glucose & -683.162579 & & -683.213798 & \\
\hline GHPPAI. $2 \mathrm{H}_{2} \mathrm{O}$ & -1401.084746 & & -1401.174903 & \\
\hline Glucose. $4 \mathrm{H}_{2} \mathrm{O}$ & -987.148587 & & -987.214789 & \\
\hline $\begin{array}{l}\Delta H^{\circ}(298 \mathrm{~K}) ; \\
\Delta \mathrm{GO}(298 \mathrm{~K})\end{array}$ & -0.059057 & -37.0584 & -0.058112 & -36.5454 \\
\hline
\end{tabular}

Table 3 Dipolar moments and polarizability tensor components of the glycine-hydroxyproline-proline-alanine (HYW), glycine-hydroxyprolineproline-alanine. $2 \mathrm{H}_{2} \mathrm{O}$ (DEW) and glycine-hydroxyproline-prolinealanine. $6 \mathrm{H}_{2} \mathrm{O}(\mathrm{HEW})$, calculated by DFT/B3LYP:3-21G procedures.

\begin{tabular}{lccc} 
& G-HP-P-Ala & G-HP-P-Ala.2 $\mathrm{H}_{2} \mathrm{O}$ & G-HP-P-Ala.6 $\mathrm{H}_{2} \mathrm{O}$ \\
\hline$\mu$ (Debye) & 8.2427 & 3.9393 & 3.0376 \\
$\alpha x x$ & 199.056 & 221.683 & 238.721 \\
$\alpha y x$ & -6.204 & -1.075 & 4.646 \\
$\alpha y y$ & 175.555 & 192.367 & 203.480 \\
$\alpha z x$ & -2.907 & 7.217 & -16.830 \\
$\alpha z y$ & -5.429 & 6.926 & 1.184 \\
$\alpha z z$ & 159.527 & 166.876 & 216.624 \\
\hline
\end{tabular}


Table 4 Wavenumbers, Raman activities, relative Raman intensities, and assignments for the computational models of GHPPAla, GHPPAla. $6 \mathrm{H}_{2} \mathrm{O}$, and GHPPAla. $2 \mathrm{H}_{2} \mathrm{O}$ in the 1000 to $800 \mathrm{~cm}^{-1}$ and in the 1500 to $1720 \mathrm{~cm}^{-1}$ spectral region.

\begin{tabular}{|c|c|c|c|c|c|}
\hline GHPPAla. (HYW) & $\begin{array}{c}\text { Exp. wn } \\
(\mathrm{BDA})\left(\mathrm{cm}^{-1}\right)\end{array}$ & $\begin{array}{c}\text { Calc. } \\
\left(\mathrm{wn} / \mathrm{cm}^{-1}\right)\end{array}$ & $\begin{array}{l}\text { Raman } \\
\text { activity }\end{array}$ & $\begin{array}{l}\text { Relative Raman } \\
\text { intensity }\left(1.0 \times 10^{15}\right)\end{array}$ & Assignment \\
\hline & & 831 & 3.9255 & 2.4163 & $\nu(\mathrm{CC}) \mathrm{HP} . \mathrm{P}+\delta\left(\mathrm{NH}_{2}\right)$ Gly \\
\hline & 814 & 839 & 2.364 & 1.4239 & $\nu(\mathrm{CN}, \mathrm{CC}) \mathrm{P} . \mathrm{HP}$ \\
\hline & & 849 & 5.3481 & 3.1361 & $\nu(\mathrm{CC}) \mathrm{HP} . \mathrm{P}+\delta\left(\mathrm{NH}_{2}\right)$ Gly \\
\hline & 856 & 868 & 4.7457 & 2.6466 & $\nu(\mathrm{CC}) \mathrm{P}$ \\
\hline & 875 & 885 & 3.5095 & 1.8727 & $\nu(\mathrm{CC}) \mathrm{P} . \mathrm{HP}$ \\
\hline & & 891 & 0.6444 & 0.3386 & $\left.\delta\left(\mathrm{CH}_{2}\right)+\delta\left(\mathrm{NH}_{2}\right)\right]$ Gly \\
\hline & 890 & 891 & 0.7561 & 0.3973 & $\nu(\mathrm{CC}) \mathrm{HP} . \mathrm{P}$ \\
\hline & & 899 & 10.8883 & 5.6060 & $\nu$ (CC)Ala \\
\hline & 914 & 909 & 2.8116 & 1.4115 & $\nu(\mathrm{CC}) \mathrm{HP}$ \\
\hline & 921 & 925 & 2.9024 & 1.4000 & $\nu(\mathrm{CC}) \mathrm{P}$ \\
\hline \multirow[t]{10}{*}{ Ratio $943 / 925=0.48 ; 0.45$} & & 929 & 2.1672 & 1.0351 & $\nu$ (CC)Gly \\
\hline & 939 & 943 & 1.3798 & 0.6368 & $\nu(\mathrm{CN}, \mathrm{CC}) \mathrm{HP} . \mathrm{P}$ \\
\hline & 960 & 952 & 2.5492 & 1.1511 & $\nu(\mathrm{CC}) \mathrm{P}$ \\
\hline & 973 & 982 & 4.5473 & 1.9115 & $\nu(\mathrm{CN}, \mathrm{CC}) \mathrm{P}$ \\
\hline & & 1011 & 5.1259 & 2.0143 & $\nu(\mathrm{CC}) \mathrm{HP}$ \\
\hline & & 1739 & 9.4974 & & $\nu(\mathrm{C}=\mathrm{O})$ Ala \\
\hline & 1684 & 1686 & 6.9657 & & $\delta(\mathrm{HNH})$ Gly \\
\hline & 1649 & 1645 & 6.5456 & & $\nu(\mathrm{C}=\mathrm{O}) \mathrm{P}$ \\
\hline & 1608 & 1611 & 4.4102 & & $\nu(\mathrm{C}=\mathrm{O}) \mathrm{HP}$ \\
\hline & & 1587 & 13.363 & & $\nu(\mathrm{C}=\mathrm{O})$ Gly. \\
\hline \multirow[t]{13}{*}{ GHPPAla. $6 \mathrm{H}_{2} \mathrm{O}$. (HEW). } & & $\begin{array}{l}\text { Wavenumbers } \\
\left(\mathrm{cm}^{-1}\right)\end{array}$ & $\begin{array}{l}\text { Raman } \\
\text { activity }\end{array}$ & $\begin{array}{c}\text { Relative Raman } \\
\text { intensity }\left(1.0 \times 10^{15}\right)\end{array}$ & Assignment \\
\hline & & 800 & 6.2704 & 4.2050 & $\nu(\mathrm{CC}) \mathrm{Ala}+\delta(\mathrm{COH}) \mathrm{HP}$ \\
\hline & & 804 & 1.3911 & 0.9225 & $\nu(\mathrm{CC}, \mathrm{CN}) \mathrm{HP} . \mathrm{P}$ \\
\hline & 814 & 812 & 2.5032 & 1.6233 & $\delta(\mathrm{COH}) \mathrm{HP}(\mathrm{H}-$ bond $)$ \\
\hline & & 817 & 4.7809 & 3.0578 & $\nu(\mathrm{CC}, \mathrm{CN}) \mathrm{HP} . \mathrm{P}+\delta(\mathrm{COH}) \mathrm{HP}(\mathrm{H}$-bond $)$ \\
\hline & 822 & 824 & 7.7074 & 4.8356 & $\delta(\mathrm{CNH})(\mathrm{H}$-bond $)++\nu(\mathrm{CN}) \mathrm{HP}$ \\
\hline & 847 & 834 & 3.9443 & 2.4082 & $\delta(\mathrm{CNH})(\mathrm{H}$-bond $)+\nu(\mathrm{CN}) \mathrm{P}$ \\
\hline & 855 & 853 & 3.0476 & 1.7682 & $\nu(\mathrm{CC}, \mathrm{CN}) \mathrm{HP} . \mathrm{P}$ \\
\hline & & 869 & 6.4866 & 3.6081 & $\nu(\mathrm{CC}, \mathrm{CN}) \mathrm{HP} . \mathrm{P}$ \\
\hline & 876 & 873 & 3.5065 & 1.9302 & $\nu(\mathrm{CC}, \mathrm{CN}) \mathrm{HP} . \mathrm{P}$ \\
\hline & 892 & 882 & 2.2932 & 1.2332 & $\nu(\mathrm{CC}, \mathrm{CN}) \mathrm{HP} . \mathrm{P}$ \\
\hline & 905 & 911 & 1.7084 & 0.8534 & $\nu(\mathrm{CC}, \mathrm{CN}) \mathrm{HP} . \mathrm{P}$ \\
\hline & & 916 & 1.1944 & 0.5892 & $\nu(\mathrm{CC}, \mathrm{CN}) \mathrm{HP} . \mathrm{P}+\delta(\mathrm{COH})$ Gly $(\mathrm{H}$-bond $)$ \\
\hline Ratio $946 / 923=0.51$ & 921 & 923 & 7.8564 & 3.8085 & $\nu(\mathrm{CC}, \mathrm{CN}) \mathrm{HP} . \mathrm{P}+\nu(\mathrm{CC}) \mathrm{Ala}$ \\
\hline
\end{tabular}


Table 4 (Continued)

\begin{tabular}{|c|c|c|c|c|c|}
\hline GHPPAla. $6 \mathrm{H}_{2} \mathrm{O}$. (HEW). & & $\begin{array}{l}\text { Wavenumbers } \\
\quad\left(\mathrm{cm}^{-1}\right)\end{array}$ & $\begin{array}{l}\text { Raman } \\
\text { activity }\end{array}$ & $\begin{array}{l}\text { Relative Raman } \\
\text { intensity }\left(1.0 \times 10^{15}\right)\end{array}$ & Assignment \\
\hline & & 929 & 3.9334 & 1.8787 & $\nu(\mathrm{CN})$ Ala.P \\
\hline & 938 & 946 & 4.0109 & 1.8376 & $\delta\left(\mathrm{NH}_{2}\right)$ Gly \\
\hline & & 947 & 1.2887 & 0.5890 & $\nu(\mathrm{CC}, \mathrm{CN}) \mathrm{HP} . \mathrm{P}+\nu(\mathrm{CC}) \mathrm{Ala}$ \\
\hline & & 950 & 4.9126 & 2.2290 & $\nu(\mathrm{CN}) \mathrm{HP}$ \\
\hline & 957 & 961 & 3.3137 & 1.4642 & $\nu(\mathrm{CC}) \mathrm{P}$ \\
\hline & 972 & 977 & 4.8358 & 2.0569 & $\nu(\mathrm{CC}) \mathrm{HP}$ \\
\hline \multirow[t]{13}{*}{ GHPPAla.2 $\mathrm{H}_{2} \mathrm{O}$. (DEW) } & & $\begin{array}{l}\text { Wavenumbers } \\
\left(\mathrm{cm}^{-1}\right)\end{array}$ & $\begin{array}{l}\text { Raman } \\
\text { activity }\end{array}$ & & Assignment \\
\hline & 823 & 824 & 3.9475 & 2.4767 & $\nu(\mathrm{CN}, \mathrm{CC}) \mathrm{HP} . \mathrm{P}+\nu(\mathrm{CC}) \mathrm{Gly}$ \\
\hline & & 832 & 5.1676 & 3.1722 & $\nu(\mathrm{CC}) \mathrm{HP}+\nu(\mathrm{CN})$ Ala \\
\hline & & 834 & 2.0035 & 1.2232 & $\delta(\mathrm{COH})$ Ala with $\mathrm{H}$-bond with $\mathrm{H}_{2} \mathrm{O}$. \\
\hline & 840 & 843 & 11.0462 & 6.5824 & $\delta\left(\mathrm{NH}_{2}\right)$ Gly $+\nu(\mathrm{CN})$ Gly \\
\hline & 854 & 847 & 1.9924 & 1.1746 & $\nu(\mathrm{CC}, \mathrm{CN}) \mathrm{P}$ \\
\hline & & 862 & 9.0105 & 5.1048 & $\nu(\mathrm{CC}, \mathrm{CN}) \mathrm{P}$ \\
\hline & 876 & 869 & 4.7195 & 2.6251 & $\nu(\mathrm{CC}) \mathrm{HP}$ \\
\hline & 884 & 879 & 2.0674 & 1.1204 & $\nu(\mathrm{CN}, \mathrm{CC}) \mathrm{HP} . \mathrm{P}$ \\
\hline & & 888 & 5.2647 & 2.7878 & $\nu(\mathrm{CC}) \mathrm{P}$ \\
\hline & 893 & 894 & 1.8132 & 0.9455 & $\nu(\mathrm{CC}) \mathrm{P}$ \\
\hline & & 895 & 5.6700 & 2.9491 & $\nu(\mathrm{C}-\mathrm{C}) \mathrm{HP}$ \\
\hline & 905 & 909 & 3.1771 & 1.5950 & $\nu(\mathrm{CC}) \mathrm{HP} . \mathrm{P}$ \\
\hline \multirow[t]{7}{*}{ Ratio $926 / 909=0.34 ; 0.33$} & 922 & 926 & 1.0804 & 0.5199 & $\nu(\mathrm{CC}) \mathrm{HP} . \mathrm{P}$ \\
\hline & 938 & 930 & 4.4189 & 2.1054 & $\nu(\mathrm{CC}) \mathrm{HP} . \mathrm{P}$ \\
\hline & 948 & 950 & 1.6006 & 0.7262 & $\nu(\mathrm{CO}) \mathrm{HP}+\nu(\mathrm{CN}) \mathrm{P}$ \\
\hline & 959 & 958 & 3.9647 & 1.7645 & $\nu(\mathrm{CN}) \mathrm{Gly}+\nu(\mathrm{CC})$ Ala \\
\hline & 970 & 965 & 2.6501 & 1.1598 & $\nu(\mathrm{CN}) \mathrm{Gly}+\nu(\mathrm{CC}) \mathrm{P}$ \\
\hline & & 983 & 4.7697 & 2.003 & $\nu(\mathrm{CN}, \mathrm{CC}) \mathrm{HP} . \mathrm{P}$ \\
\hline & & 1007 & 5.0782 & 2.0140 & $\nu(\mathrm{CN})$ Gly.P $+\delta\left(\mathrm{NH}_{2}\right)$ Gly \\
\hline
\end{tabular}

Raman spectra of young women because the attached water content inside the collagen fiber is higher in the young participants, so the polarizability became higher and, as a consequence, the intensity increased.

\subsection{Vibrational Assignments}

Calculated band assignments, Raman activities, and relative Raman intensities for these systems are given in Table 4. Relative Raman intensities were calculated according to the following equation:

$I_{i}=f\left(\nu_{0}-\nu_{i}\right) 4 S_{i} / \nu_{i}\left[1-\exp \left(-h c \nu_{i} / k T\right)\right]$, where $\nu_{0}$ is the laser excitation frequency in $\mathrm{cm}^{-1}$ units $(785 \mathrm{~nm}$ to $\left.12738.8535 \mathrm{~cm}^{-1}\right), \nu_{i}$ is the vibrational wave number of the $i$ th normal mode in $\mathrm{cm}^{-1}$ units, $S_{i}$ is the calculated Raman activities of the normal mode $\nu_{i}$, and $f$ is a constant value equal to one (the value of 10 to 12 can be used). $H, k, c$, and $T$ are Planck, Boltzmann, light speed, and temperature (298 K), respectively. ${ }^{27}$ We will discuss here the 1000 to $800 \mathrm{~cm}^{-1}$, hydroxyproline and proline spectral region, and the region between 1500 and $1720 \mathrm{~cm}^{-1}$ called amide I. Calculated wave numbers, Raman activities, and Raman intensities are given in Table 4 with the approximate calculated assignment for the corresponding amino acids, already abbreviated as HP for hydroxyproline, $\mathrm{P}$ for proline, Gly for glycine, and Ala for alanine. 
For comparison, we provide in the same table the experimental wave numbers obtained by band deconvolution analysis.

As we pointed out, the experimental ratio $938: 922 \mathrm{~cm}^{-1}$ was considered a marker of hydration. ${ }^{6}$ The experimental and calculated values of this ratio have the following values for HYW, HEW, and DEW: $1.48 \pm 0.09,1.60 \pm 0.13$, and $1.46 \pm 0.07$ (experimental values); 0.48, 0.51, and 0.34 considering Raman activities, and $0.45,0.47$, and 0.33 considering relative Raman intensities (calculated values considering the Raman activities and the relative Raman intensities), respectively. The experimental ratio for the elderly women increases compared with the young and diabetic women, and the ratio of the diabetic women is a little under the ratio of young and elderly women. The same trends are observed in the calculated values.

\subsection{Amide I Band}

Assignments of the vibrational spectrum for the band amide I were found in different publications. Movasaghi et al. ${ }^{21}$ reported in a review article a long list of wave numbers from 415 to $3550 \mathrm{~cm}^{-1}$ of the Raman spectra of biological tissues. Although, the Movasaghi information is valuable, their wave numbers do not express the confidence interval of spectroscopic measurement. Another interesting review is the work of Barth on the infrared absorption of amino acid side chains. ${ }^{28}$ Because the amino acids are molecules of lower (or no) symmetry, Barth quoted values must be coincident in the Raman spectra of the amino acids. In one of our recent works on the confocal Raman spectra of skin dermis, we summarized vibrational assignments of different authors for amide I bands. ${ }^{18}$ According to Nguyen et $\mathrm{al}^{2}$, the amide I band assigned to collagen I is centered at $1668 \mathrm{~cm}^{-1}$ in the Raman spectra of the skin.

In Nguyen et al.'s paper, no further assignments in the skin dermis were done for the amide I spectral region. The amino acid content in collagen is variable. According to Goisses, ${ }^{17}$ the main residual components of the alpha- 1 chain are glycine with a value of 345,114 for HP, 127 residues for proline, and 127 residues for alanine; the alpha- 2 chain has the values of 346 , 99, 108, and 111 residues for the same amino acids described above. The band for the vibrational mode $\nu(\mathrm{C}=\mathrm{O})$ of the carbonyl in these amino acids should in principle vary in wave number position and in intensity, according to the number of residues presenting in collagen content. In the region of amide I in the Raman spectra of HEW's skin, the observed shift to lower wave numbers is due to the hydrogen formation between the amino acid and water. Moreover, for the DEW, it is due to the hydrogen bond formation between the amino acid chains of collagen with residual water and glucose, principally through the oxydrilic groups.

In our model systems composed by the four main amino acids interacting with water molecules through hydrogen bonds, the calculated wave numbers come from the B3LYP procedure using a $3-21 \mathrm{G}$ basis set, and the results are listed in Table 4. Experimental wavenumbers obtained by band deconvolution analysis are given in Table 1 . Figure 1 shows the Gaussian fitting of amide I profile bands for the confocal Raman spectra of HYW, HEW, and DEW. The band found at 1613 (DEW), 1609 (HEW), and 1608 (HYW) $\mathrm{cm}^{-1}$ has the following assignments: according to Venyaminov and Kalnin ${ }^{29}$, these bands correspond to the $\delta\left(\mathrm{NH}_{2}\right)$ of asparagine or glutamine. Movasaghi et al. ${ }^{21}$ assigned these bands to the same $\delta\left(\mathrm{NH}_{2}\right)$ mode as cytosine. According to Huang et al., ${ }^{30}$ the amide I bands found at 1638 (DEW), 1636 (HEW), and $1635 \mathrm{~cm}^{-1}$ (HYW) can be assigned to a vibrational mode pertaining to the $\nu_{\mathrm{s}}\left(\mathrm{CN}_{3} \mathrm{H}_{5}^{+}\right)$of arginine. ${ }^{28}$

Agreeing with the wave numbers where the vibrational mode occurs, we think that the participation of the $(\mathrm{C}-\mathrm{N})$ internal coordinate must be of little extension and two conjugated $\nu(\mathrm{C}:: \mathrm{N})$ internal coordinates because the protonation has higher participation in the description of the symmetrical stretching mode. The preferable nomenclature to describe this mode is $\nu s(\mathrm{C}:::: \mathrm{N})+\nu(\mathrm{C}-\mathrm{N})+\delta\left(\mathrm{NH}_{2}\right)+\delta(\mathrm{NH})$ because in the same region the bending $\delta\left(\mathrm{NH}_{2}\right)$ and $\delta(\mathrm{NH})$ participate. Amide I bands found at 1656 (DEW), 1657 (HEW), and $1665 \mathrm{~cm}^{-1}$ (HYW) can be assigned to the collagen content in the reticular dermis of all the 30 volunteers without age discrimination.

These assignments are coincident with the proposal of Nguyem et al., ${ }^{2,12}$ amide I band found at 1671 (DEW), 1673 (HEW), and $1684 \mathrm{~cm}^{-1}$ (HYW) by the deconvolution process is assigned to the $\nu(\mathrm{C}=\mathrm{O})$ of alanine or $\beta$-turns by Stuart and Movasaghi et al., ${ }^{21}$ but this last assignment is general for proteins. Deconvolution process by Gaussian fitting of the amide I band between 1720 and $1580 \mathrm{~cm}^{-1}$ also gives bands at 1699 (DEW), 1697 (HEW), and $1696 \mathrm{~cm}^{-1}$ (HYW). These bands are assigned to $\delta\left(\mathrm{NH}_{2}\right)$ of glycine. Integrated area for the amide I band measured in the range of 1720 to $1580 \mathrm{~cm}^{-1}$ has a value of $77 \%$ for the HYW, $27 \%$ being expressive due to the higher collagen quantity. It is well known that one of the factors of the triple-helical structure in type I collagen is the hydrogen bonds of terminal carbonyl groups of hydroxyproline and glycine in opposite sides of the triple-helical structure or on the same side of the chain structure, which is called interchain association.

The other possibility of binding water within the triple-helix structure is called interchain and occurs between opposite chains in the triple-helix conformation. The first case forms a ring of water interacting with the carbonyl groups of hydroxyproline and with the $-\mathrm{C}=\mathrm{O}$ group of glycine; in the second case, water molecules are binding, which forms a bridge between opposite sides of the triple-helix. ${ }^{1}$

Nguyen et al. ${ }^{2}$ pointed out ratios of integrate intensities, to evaluate water/collagen interactions. In our case, the selected quotients of experimental Raman intensity bands (in arbitrary units) are: $1649 / 1665 \mathrm{~cm}^{-1} 1 \Rightarrow 0.23 / 0.84=0.27$ (HYW), $1657 / 1678 \mathrm{~cm}^{-1} \Rightarrow 0.30 / 0.59=0.51$ for HEW, and $1656 /$ $1671 \mathrm{~cm}^{-1} \Rightarrow 0.29 / 0.65=0.45$ for DEW, giving the values of $22 \%, 41 \%$, and $37 \%$ of water/collagen interactions. We can translate this observation and state that the HYW have inside the collagen triple-helix lower water contents, with higher water contents in DEW and HEW with comparable values. Such similar ratios for the three cases are the interaction Gly/HP, $13.369 / 4.4102=3.03$ in the calculated spectrum of the young woman volunteers, Ala/HP, 12.6874/5.7455 = 3.76 in the calculated spectrum of the HEW, and the interaction $\mathrm{P} /$ Ala, $13.5756 / 4.658=2.91$ for the diabetic women. The glycine-hydroxyproline-proline-alanine model does not contain water and was considered to represent the young woman volunteers. Wavenumber shift to low energy region was also found in the calculated spectra of the Gly.HP.P.Ala (HYW), Gly.HP.P.Ala. $6 \mathrm{H}_{2} \mathrm{O}$ (HEW), and the Gly.HP.P.Ala. $2 \mathrm{H}_{2} \mathrm{O}$, representing the DEW. Stretching $\nu(\mathrm{C}=\mathrm{O})$ for proline goes from 1645 to $1618 \mathrm{~cm}^{-1}$; for hydroxyproline, it goes from 1611 to $1605 \mathrm{~cm}^{-1}$; for alanine the shift goes down from 1739 to $1675 \mathrm{~cm}^{-1}$; and for the amino acid glycine, the wave number 
Table 5 Lycine-hydroxyproline-proline-alanine systems with water. Carbonyl stretching assignments. Experimental wave number values obtained by band deconvolution analysis (Gaussian fitting).

\begin{tabular}{|c|c|c|c|c|c|}
\hline System & Exp. wavenumber & Calc. wn. & Raman activity & Relative Raman intensity $\left(1.0 \times 10^{15}\right)$ & Assignment: $\nu(\mathrm{C}=\mathrm{O})$ \\
\hline \multirow[t]{5}{*}{ Gly.HP.P.Ala (HYW) } & & 1739 & 9.4974 & 0.9933 & $\nu(C=O)$ Ala \\
\hline & 1684 & 1686 & 6.9657 & 0.7891 & $\delta(\mathrm{HNH})$ Gly \\
\hline & 1649 & 1645 & 6.5456 & 0.7898 & $\nu(\mathrm{C}=\mathrm{O}) \mathrm{P}$ \\
\hline & 1608 & 1611 & 4.4102 & 0.5612 & $\nu(\mathrm{C}=\mathrm{O}) \mathrm{HP}$ \\
\hline & & 1587 & 13.363 & 1.7665 & $\nu(\mathrm{C}=\mathrm{O})$ Gly. \\
\hline \multirow[t]{5}{*}{ Gly.HP.P.Ala.6 $\mathrm{H}_{2} \mathrm{O}$. (HEW) } & 1697 & 1680 & 10.6094 & 1.2129 & $\left.\delta\left(\mathrm{NH}_{2}\right) \mathrm{Gly}\right)$ \\
\hline & 1646 & 1650 & 5.7455 & 0.6879 & $\nu(\mathrm{C}=\mathrm{O}) \mathrm{P}$ \\
\hline & 1609 & 1602 & 3.3766 & 0.4358 & $\nu(\mathrm{C}=\mathrm{O}) \mathrm{HP}$ \\
\hline & 1589 & 1596 & 12.6874 & 1.6533 & $\nu(\mathrm{C}=\mathrm{O})$ Ala \\
\hline & & 1548 & 8.878 & 1.2496 & $\nu(\mathrm{C}=\mathrm{O})$ Gly- \\
\hline \multirow[t]{5}{*}{ Gly.HP.P.Ala. $2 \mathrm{H}_{2} \mathrm{O}$. (DEW) } & 1699 & 1681 & 4.328 & 0.4941 & $\left.\delta\left(\mathrm{NH}_{2}\right) \mathrm{Gly}\right]$ \\
\hline & 1671 & 1675 & 4.658 & 0.5366 & $\nu(\mathrm{C}=\mathrm{O}) \mathrm{Ala}$ \\
\hline & 1613 & 1618 & 13.5756 & 1.7086 & $\nu(\mathrm{C}=\mathrm{O}) \mathrm{P}$ \\
\hline & 1589 & 1605 & 2.1467 & 0.2758 & $\nu(\mathrm{C}=\mathrm{O}) \mathrm{HP}$ \\
\hline & & 1581 & 15.9843 & 2.1333 & $\nu(\mathrm{C}=\mathrm{O})$ Gly \\
\hline
\end{tabular}

shift is from 1587 to $1581 \mathrm{~cm}^{-1}$ between the spectra of HYW and DEW, respectively. For the Raman spectrum of HEW, the $\nu(\mathrm{C}=\mathrm{O})$ was assigned at $1548 \mathrm{~cm}^{-1}$.

In Table 5, we add the correlative experimental wave number in the corresponding column for comparison. With the exception of $\nu(\mathrm{C}=\mathrm{O})$ of alanine calculated at $1739 \mathrm{~cm}^{-1}$, all the $\nu(\mathrm{C}=\mathrm{O})$ stretching of the amino acids that form the three models can be correlated with the experimental values obtained by band deconvolution analysis. The following wavenumbers $1620 \mathrm{~cm}^{-1}$ (HYW), $1609 \mathrm{~cm}^{-1}$ (HEW), and $1589 \mathrm{~cm}^{-1}$ (DEW) from the calculated spectra follow the experimental trends observed in the profile of the spectra of amide I band: for the young women, the amide I band is located at the right side; for the elderly women, the amide I band is in the middle; and for the diabetic women, the $\nu(\mathrm{C}=\mathrm{O})$ bands appear at lower energy. Why are there delocalized bands when we compared the amide I band of young, elderly, and elderly diabetic women? The answer is that: the strength of the $\mathrm{C}=\mathrm{O}$ bonds of amino acids of collagen becomes weaker by charge transfer to form bond interactions with the hydrogen of water (H-bond), and in the case of the DEW, glucose can also form H-bonds with the conformational amino acids of the triple-helix. Then, when the $-\mathrm{C}=\mathrm{O}$ bond becomes weaker, its wavenumber decreases. The other reason to complete this argument is that: carboxylate group of hydroxyproline in the presence of water forms a carboxylate resonance group with delocalized bonds, which are weaker than the double bond and a little stronger than the single $\mathrm{C}-\mathrm{O}$ bond. This anionic structure can form $\mathrm{H}$-bonds with water in monomeric form and with the hydronium ion. In the DEW, glucose is present not only in the tail of the collagen fibers but also in the interstitial space among the fibers of collagen, and it forms
H-bonds through its hydroxyl groups or with its aldehyde terminal with chemical groups of the amino acids, which form the collagen fibers.

\section{Conclusions}

As we pointed out earlier, ${ }^{18}$ the biggest changes were found in bands with average values at $958 \mathrm{~cm}^{-1}$ assigned to the vibrational mode: $\nu(\mathrm{CC}) 14,0 \%+\nu(\mathrm{C}-\mathrm{COOH}) \quad 12.5 \%+\delta(\mathrm{NC}[\mathrm{COOH}]) 10.1 \%$ and at $891 \mathrm{~cm}^{-1}$ assigned as $\nu(\mathrm{CC})$ ring $22.5 \%+$ $\nu(\mathrm{CN}) \operatorname{ring} 18.8 \%+\delta(\mathrm{C}-\mathrm{C}-\mathrm{COOH}) 13.6 \% ; \nu(\mathrm{CO}) 14.4 \%+$ $\nu(\mathrm{CC})$ ring $10.3 \%+\delta(\mathrm{C}-\mathrm{C}-\mathrm{COOH}) 10.0 \%$, for both amino acids proline and hydroxyproline, which are values of wave numbers that can be considered markers of glycation process due to the strong variations of their intensities. The water content inside the collagen fibers was determined, according to Nguyen at al., ${ }^{12}$ through the ratio of the integrated areas of two select bands, in our case between the bands assigned as $\beta$-structure and turns and bends (collagen). The results indicate lower water content for the HYW group of volunteers, and similar and higher water contents for the DEW and HEW groups. Concerning AGEs in the Raman spectra, pentosidine and glucosepane have weak intensity and present overlapping bands inside the profile of the hydroxyproline and proline bands between 1000 and $800 \mathrm{~cm}^{-1}$. Instead of this difficulty, second derivative techniques and band deconvolution analysis reveal the presence of pentosidine at 914,825 , and $970 \mathrm{~cm}^{-1}$, and for glucosepane at 809,980 , and $970 \mathrm{~cm}^{-1}$; the last one is coincident with the assignment of pentosidine presence. The bands of these AGEs can be assigned according to the DFT/B3LYP:3$21 \mathrm{G}$ calculations as follows: $980 \mathrm{~cm}^{-1}$ (glucosepane), $\nu(\mathrm{CN})+$ $\nu(\mathrm{CC})+\delta(\mathrm{HCH})$ wagg; $963 \mathrm{~cm}^{-1}$ (pentosidine, glucosepane), 
$\nu(\mathrm{CO})\left(\mathrm{COH}\right.$ terminals); $917 \mathrm{~cm}^{-1}$ (pentosidine), $\nu(\mathrm{CC})+$ $\delta(\mathrm{HCH})$ twist $+\delta(\mathrm{NCN}) ; 826 \mathrm{~cm}^{-1}$ (pentosidine), $\rho\left(\mathrm{CH}_{2}\right)+$ $\nu(\mathrm{CO})+\delta(\mathrm{HCH})$ wagg $+\nu(\mathrm{CN}) ; \quad 813 \mathrm{~cm}^{-1} \quad$ (glucosepane), $\nu(\mathrm{CN})+\rho(\mathrm{C}=\mathrm{O}) \uparrow$. Assignments of these AGEs and band coincidences with the confocal Raman spectra of HEW and DEW were informed in Ref. 35. For the amide I band for all volunteers, the observed shift and intensity decrease were discussed in an earlier paper in which the analysis of the spectral data considered the amide I normalization. ${ }^{18}$ The glycation process degrades collagen, so its concentration in the skin dermis becomes lower, comparing the collagen content of HYW and HEW: less collagen concentration, less band intensity. For diabetic women, two factors are conjugated to explain the wave number shift of the $\mathrm{C}=\mathrm{O}$ stretching and the intensity decrease compared with HYW and HEW: (a) the presence of glucose requires water breaking the $\mathrm{H}$-bonds from the collagen fibers, so the polarizability becomes lower than in the case of HYW and HEW. With lower polarizability, the intensity of the bands decreased. (b) The glycation process causes lower collagen concentration by degradation, so band intensity decreased. Chemical reactions were proposed and computationally simulated to interpret the intensity of the hydroxyproline, proline, and amide I bands in the three groups of volunteers. In these reactions, the reactants were GHPPAla. $6 \mathrm{H}_{2} \mathrm{O}+$ glucose, and the reaction products of water as ligand interchange were GHPPAla. $2 \mathrm{H}_{2} \mathrm{O}+$ glucose $.4 \mathrm{H}_{2} \mathrm{O}$. The system modeling presented in this study was sufficient to interpret the experimental observations in the Raman spectra of the three groups of volunteers. The glycine-hydroxyproline-proline-alanine model with and without water was simulated through DFT theory using the B3LYP functional with a 3-21G basis set in all cases. Geometries of the systems were obtained, and the Raman spectra were calculated. Experimental wave numbers of the skin dermis of all volunteers agree well with the calculated ones. The computational models were able to interpret the experimental trends in wave numbers shift and wavenumber ratios used for water marker content.

\section{Disclosures}

The authors declare no conflicts of interest regarding this work.

\section{Acknowledgments}

We are grateful to the Brazilian agencies FINEP, CNPq, and FAPESP (2012/21904-2), and to CAPES for financial support. Téllez thanks the FVP-UNIVAP for the grant. A. A. Martin thanks CNPq (307809/2013-7). L. dos Santos and Ramu Rajasekaran acknowledge CAPES wide project number (88881.062862/2014-01) and (88881.062547/2014-01), respectively, for financial support.

\section{References}

1. J. Bella et al., "Hydration structure of a collagen peptide," Structure 3, 893-906 (1995).

2. T. Nguyen et al., "Characterization of type I and IV collagens by Raman microspectroscopy: identification of spectral markers of the dermoepidermal junction," Spectrosc. Int. J. 27(5-7), 421-427 (2012).

3. Q. Zhang et al., "Raman microspectroscopic and dynamic vapor sorption characterization of hydration in collagen and dermal tissue," Biopolymers 95, 607-615 (2011).

4. L. Pereira et al., "Confocal Raman spectroscopy as an optical sensor to detect advanced glycation end products of the skin dermis," Sens. Lett. 13, 791-801 (2015).
5. M. G. Tosato et al., "Raman spectroscopic investigation of the effects of cosmetic formulations on the constituents and properties of human skin," Photomed. Laser Surg. 30, 85-91 (2012).

6. P. Caspers, "In vivo skin characterization by confocal Raman microspectroscopy," PhD dissertation, E, 35 (2003).

7. Z. Huang et al., "Rapid near-infrared Raman spectroscopy system for real-time in vivo skin measurements," Opt. Lett. 26, 1782-1784 (2001).

8. P. J. Caspers et al., "Combined in vivo confocal Raman spectroscopy and confocal microscopy of human skin," Biophys. J. 85, 572-580 (2003).

9. J. Zhao et al., "Real-time Raman spectroscopy for noninvasive in vivo skin analysis and diagnosis," Recent Adv. Biomed. Eng. 1, 455-474 (2010).

10. J. V. Glenn et al., "Confocal Raman microscopy can quantify advanced glycation end product (AGE) modifications in Bruch's membrane leading to accurate, nondestructive prediction of ocular aging," FASEB J. 21, 3542-3552 (2007).

11. N. Mainreck et al., "Rapid characterization of glycosaminogly cans using a combined approach by infrared and Raman microspectroscopies," J. Pharm. Sci. 100, 441-450 (2011).

12. T. T. Nguyen et al., "Raman comparison of skin dermis of different ages: focus on spectral markers of collagen hydration," Spectrosc. Int. J. 44, 1230-1237 (2013).

13. M. Guilbert et al., "Probing non-enzymatic glycation of type I collagen: a novel approach using Raman and infrared biophotonic methods," Biochim. Biophys. Acta 1830, 3525-3531 (2013).

14. P. K. Oliveira et al., "Skin biochemical composition analysis by Raman spectroscopy," Rev. Bras. Eng. Biomed. 28 (2012).

15. N. C. Avery and A. J. Bailey, "The effects of the Maillard reaction on the physical properties and cell interactions of collagen," Pathol. Biol. 54(7), 387-395 (2006).

16. M. J. Frisch et al., Gaussian 09 Revision D.01, Gaussian Inc., Wallingford, Connecticut (2009).

17. A. P. A. Goissis, "Structural analysis of type I collagen: structure activities relationships," Master's Thesis, Universidade de Sao Paulo (2007). http://www.teses.usp.br.

18. C. Tellez et al., "RM1 semi empirical and DFT:B3lyp/3-21g theoretical insights on the confocal Raman experimental observations in qualitative water content of the skin dermis of healthy young, healthy elderly and diabetic elderly women," Spectrochim. Acta Part A 149, 1009-1019 (2015).

19. A. R. Guerrero and R. F. Aroca, "Surface-enhanced Raman scattering of hydroxyproline," J. Raman Spectrosc. 43, 478-481 (2012).

20. H. Schulz and M. Baranska, "Identification and quantification of valuable plant substances by IR and Raman spectroscopy," Vib. Spectrosc. 43, 13-25 (2007).

21. Z. Movasaghi et al., "Raman spectroscopy of biological tissues," Appl. Spectrosc. Rev. 42, 493-541 (2007).

22. C. A. T. Soto et al., "Surface enhanced Raman scattering, electronic spectrum, natural bond orbital, and Mulliken charge distribution in the normal modes of diethyldithiocarbamate copper (II) complex, [Cu(DDTC)2]," Spectrochim. Acta Part A 116, 546-555 (2013).

23. C. Anilton et al., "DFT: B3lyp/6-311g (d, p) vibrational analysis of bis-(diethyldithiocarbamate)zinc (II) and natural bond orbitals," Spectrochim. Acta Part A 105, 251-258 (2013).

24. C. A. T. Soto et al., "Fourier transform infrared and Raman spectra, vibrational assignment and abinitio calculations of terephthalic acid and related compounds," Spectrochim. Acta A Mol. Biomol. Spectrosc. 57, 993-1007 (2001).

25. P. Lasch et al., "Imaging of human colon carcinoma thin sections by FT-IR microspectroscopy," Infrared Spectrosc. New Tool Med. 3257, 187-197 (1998).

26. F. J. Tessier, "The Maillard reaction in the human body. The main discoveries and factors that affect glycation," Pathol. Biol. 58, 214-219 (2010).

27. I. B. Cozar et al., "Raman, SERS and DFT study of atenolol and metoprolol cardiovascular drugs," Rom. J. Phys. 55, 772-781 (2010).

28. A. Barth, "The infrared absorption of amino acid side chains," Prog. Biophys. Mol. Biol. 74, 141-173 (2000).

29. S. Y. Venyaminov and N. N. Kalnin, "Quantitative IR spectrophotometry of peptide compounds in water $\left(\mathrm{H}_{2} \mathrm{O}\right)$ solutions. I, spectral parameters of amino acid residue absorption bands," Biopolymers 30, 12431257 (1990) 
30. Z. Huang et al., "Near-infrared Raman spectroscopy for optical diagnosis of lung cancer," Int. J. Cancer 107, 1047-1052 (2003).

Claudio Alberto Téllez Soto was a full professor in inorganic chemistry at the UFF University, Brazil (retired). Currently, he is working as a scientific researcher in the Institute of Research and Development (IP\&D), University of Vale do Paraíba (UNIVAP), Brazil. His research area is vibrational spectroscopy applied to all the chemistry branches, medicine, odontology, and biological sciences. He has guided 20 master's degree and $12 \mathrm{PhD}$ students and authored more than 100 papers.

Liliane Pereira received her bachelor's degree from the University of Alfenas, Brazil, and her master's degree in biomedical engineering from the Universidade do Vale do Paraíba, Brazil. She is currently working with vibrational spectroscopy applied to skin aging and glycation analysis for her $\mathrm{PhD}$ in biomedical engineering from Universidade do Vale do Paraiba, Brazil.

Laurita dos Santos received her MSc degree and $\mathrm{PhD}$ in applied computing from the National Institute for Space Research (INPE), Brazil, in 2009 and 2013, respectively. She is currently pursuing her postdoctoral research in biomedical engineering at the Universidade do Vale do Paraiba, São José dos Campos, Brazil.
Ramu Rajasekaran received his $\mathrm{PhD}$ in physics from Anna University, Chennai. He is currently working as an assistant professor in the Department of Physics, Bannari Amman Institute of Technology, Sathyamangalam, India. He worked as a postdoctoral fellow in Dr. Airton A. Martin's lab in the area of biomedical applications of Raman spectroscopy. He has particular interest in optical diagnosis of cancer, photodynamic therapy, and therapy monitoring.

Priscila Fávero received her bachelor's degree in physics from the University of Brasilia in (UNB) 2004, her master's degree in experimental physics from UNB in 2004, and her PhD in theoretical physics from UNB and Universitaet Paderborn in 2009. She is a professor at the Universidade do Vale do Paraíba, Brazil. She did her postdoctoral research at the Federal University of $A B C$ and Advanced Studies of the Department of Science and Technology, Aeronautics (IEAv/DCTA).

Airton Abrahão Martin received his bachelor's degree, master's degree, and $\mathrm{PhD}$ in physics from the State University of Londrina in 1985, University of São Paulo in 1988, and University of Toronto and Unicamp in 1995, respectively. He received his MSc degree from the University of Toronto, Canada, in 1991. He did his postdoctorate at the Max Planck Institute for Festokoperforschung in 1999. Currently, he is an associate professor, coordinator of the Biomedical Engineering Graduate Program, and head of LEVB, UNIVAP, Brazil. 